\title{
EREBEA
}

Revista de Humanidades

y Ciencias Sociales

NúM. 3 (2013), pp. 117-134

ISSN: 0214-0691

\section{LA VIDA ANTE LA INQUISICIÓN: BIOGRAFÍA Y PROCESOS INQUISITORIALES EN CASTILLA A FINES DEL MEDIEVO*}

\author{
María del Pilar Rábade Obradó \\ Universidad Complutense de Madrid
}

Resumen

Este trabajo se refiere a las posibilidades de los procesos inquisitoriales como fuentes para la reconstrucción de las biografías de los reos. Tras una primera parte metodológica, en la que se discuten los límites y posibilidades de los procesos inquisitoriales como fuentes biográficas, se ofrecen tres ejemplos prácticos. Dichos ejemplos están relacionados con tres judeoconversos juzgados por la Inquisición durante sus primeros años de actividad: el sacerdote Andrés González de Alía, el comendador de la Orden Militar de Santiago Juan de Pineda y Fernando de la Fuente, veterano de las guerras de Granada.

\section{Abstract}

This work refers to the possibilities of the Inquisitorial trials as documentary sources for the reconstruction of the biographies of the convicts. After the first methodological part, in which there are discussed the limits and possibilities of the inquisitorial trials as biographical sources, this work offers three practical examples. These examples are related to three judeoconverts judged by the Inquisition for his first years of activity: the priest Andrés González de Alía, the commander of the Military Order of Santiago Juan de Pineda and Fernando de la Fuente, veteran of the Granada War.

\section{Palabras Clave}

Castilla, siglo XV, judeoconversos, Inquisición, biografía.

\section{KEYWORDS}

Castile, XVth Century, judeoconverts, Inquisition, biography.

Fecha de recepción: 1 de julio de 2013 Fecha de aceptación: 31 de julio de 2013

* Este trabajo se ha realizado dentro del Proyecto de Investigación de la Secretaría de Estado de Investigación HAR2010-16762. 

En una entrevista que realizó hace ya algunos años la revista Manuscrits a Giovanni Levi, uno de los más destacados expertos en microhistoria, el entrevistador se expresaba de la siguiente manera':

Lo que siempre nos ha inquietado de la biografía es que, a través de las fuentes documentales, el personaje reflejado sea el gran hombre, el individuo anormal. Lo que queríamos subrayar es el problema de la anormalidad intrinseca del personaje que sale en la documentación. Desde el momento en que sale en la documentación ya es un personaje que tiene algo de 'anormal'. Nos interesa, estudiando el mundo de los moriscos, el mundo de los judeoconversos a través de la documentación inquisitorial, que se pueden hacer ciertamente unas biografias preciosas.

Aunque la cita es demasiado larga, y quizá también demasiado coloquial en su expresión, he considerado pertinente iniciar con ella este trabajo, pues apunta una cuestión evidente: la gran dificultad a la hora de biografiar a lo que podemos denominar "gente corriente", a la par que apunta también una solución, si bien claramente parcial: aproximarse a la biografía de moriscos y judeoconversos, recurriendo para ello a las fuentes inquisitoriales.

El recurso a la documentación del Santo Oficio, por tanto, no sólo nos puede ayudar a trazar las peripecias biográficas de esa "gente corriente" a la que se hacía alusión más arriba, pues a ella pertenecían, en su gran mayoría, moriscos y judeoconversos, sino que también es una ayuda imprescindible para aproximarnos a la realidad de esos dos grupos sociales. Si nos centramos ya en el caso concreto de los judeoconversos, es preciso reconocer que no siempre resulta fácil la reconstrucción de sus biografías; a los problemas y dificultades vinculados con la elaboración de cualquier biografía de un personaje medieval (carencia de fuentes, carácter fragmentario de las mismas...), se añade uno especifico, a la par que muy importante y de relevantes consecuencias: el problema para determinar si el biografiado es de ascendencia judía, o no.

1 José Luis Beltrán Moya; Antonio Espino López y Ricardo García Cárcel, “Antropología y microhistoria: conversación con Giovanni Levi”, Manuscrits. Revista d'Història Moderna, 11 (1993), 16-28, y en concreto p. 27. 
La sangre hebrea que corría por sus venas se convirtió, casi desde el primer momento, en un estigma para los cristianos nuevos. Por ese motivo, muchos trataron de soslayar, cuando no directamente de ocultar, sus orígenes hebreos. Así, rastrear a los judeoconversos en las fuentes documentales no siempre resulta sencillo, aunque a veces los papeles de tiempos pasados se pueden expresar con mucha claridad. Véase, si no, el caso de dos de los más ilustres colaboradores de los Reyes Católicos, Alfonso de Ávila y Fernando Álvarez de Toledo.

A su condición de judeoconversos alude de forma muy directa el cronista de los Reyes Católicos Fernando del Pulgar. Lo hace en una de sus más conocidas letras, dirigida al cardenal Mendoza, en la que se lamentaba del intento de soslayar a los judeoconversos que residían en Guipúzcoa, pese a la paradoja que suponía, entre otras cosas porque eran muchos los hijos de esa tierra que acudían a recibir una formación en casa de judeoconversos como los dos citados ${ }^{2}$. Sin embargo, tanta claridad no suele ser la norma, sino más bien la excepción. En estas circunstancias, las fuentes procedentes de la actividad del Santo Oficio se convierten en un recurso fundamental para proceder a la elaboración de biografías de hombres y mujeres de los que sabemos, con toda seguridad, que eran judeoconversos.

Pero ¿puede realmente utilizarse la documentación inquisitorial como fuente para proceder a la reconstrucción de trayectorias biográficas? Y más concretamente, ¿pueden emplearse los procesos inquisitoriales para biografíar a los sujetos de dichos procesos? La respuesta a ambas preguntas parece ser, irremediablemente, afirmativa, habida cuenta de que ya hay historiadores que han recurrido a las fuentes del Santo Oficio, y más específicamente a las causas de fe, para trazar las peripecias biográficas de los encausados ${ }^{3}$.

También es verdad que se trata de trabajos que se refieren a la Edad Moderna. Y tal situación es importante de tener en cuenta, pues fue ya a lo largo del XVI cuando la Inquisición adoptó la costumbre de imponer a los reos la obligación de realizar un recorrido por lo que había sido su vida hasta ese momento ${ }^{4}$, el "discur-

2 Fernando del Pulgar, Letras. Glosas a las Coplas de Mingo Revulgo, ed. J. Domínguez Bordona, Madrid: Espasa-Calpe, 1929, p. 150, Letra XXXI.

3 Véase, por ejemplo, Richard L. Kagan y Abigail Dyer (eds.), Inquisitorial Inquiries: the Brief Lives of Secret Jews and Other Heretics, Baltimore: Johns Hopkins University Press, 2011 ( $2^{\mathrm{a}} \mathrm{ed}$.). Nótese que se trata de autores anglosajones, que son los que, mayoritariamente hasta el momento, han usado las fuentes inquisitoriales para tratar de esbozar biografías de los reos; incluso, Kagan y Dyer (eds.), Inquisitorial Inquiries..., p. 6, nota no 5, aluden a lo inhabitual de su utilización por los investigadores.

4 Como recuerda James S. Amelang, "Tracing Lives: the Spanish Inquisition and the Act of Autobiography”, en J. Arianne Baggerman, Rudolf M. Dekker y Michael James Mascuch (eds.), Controlling Time and Shaping the Self: Developments in Autobiographical Writing since the Sixteenth Century, Leiden, Brill, 2011, pp. 33-48, y en concreto p. 36, fue en 1561 cuando, en las instrucciones del inquisidor general Valdés, se impuso la obligación de que los reos procedieran a relatar el "discurso de su vida", aunque insiste en que posiblemente ya existía previamente una cierta costum- 
so de su vida" ${ }^{5}$, que ofrece amplias posibilidades a los investigadores con interés por adentrarse en estudios biográficos ${ }^{6}$. Diferente es la realidad en relación con los primeros momentos de la actividad inquisitorial, cuando los inquisidores se sentían literalmente abrumados por el ingente trabajo a realizar ${ }^{7}$, de tal modo que aceleraban al máximo los procesos, en los que no se conminaba a los reos a contar la historia de su vida, aunque dicha historia se iba haciendo presente, en mayor o menor medida, según se desarrollaba la causa.

En cualquier caso, los procesos inquisitoriales son una fuente biográfica no exenta de problemas, que deben ser debidamente valorados. Para mostrar esos problemas, se va a recurrir a diversos ejemplos relacionados con la actividad del tribunal inquisitorial de Toledo durante sus primeros años de existencia.

Algunos PROBlemas de los PROCESOS INQUisitoriales COMO FUENTES BIOGRÁFICAS

Como es bien sabido, en las causas de fe se otorgaba la palabra al reo. Cuando en el siglo XIII se procedió a la fundación de la Inquisición, se impuso "la necesidad de arrebatar al precio que fuera una confesión" ${ }^{8}$, de modo que se le daba la palabra el hereje, para que confesara sus errores, para que delatara a sus cómplices, $y$, en última instancia, para que se arrepintiera y se le pudiera reintegrar al seno de la Iglesia.

Así, en los procesos inquisitoriales el hereje tomaba la palabra, se explicaba, contaba una historia, su historia. De modo que, al menos en alguna medida, se puede considerar que el suyo es un relato autobiográfico, lo que podría considerarse una autobiografía espiritual ${ }^{9}$, pues, evidentemente, no se trata de una nar-

bre en este sentido, que de alguna forma hunde sus raíces en los primeros momentos de la actividad de la Inquisición española a fines del siglo XV.

5 Kagan y Dyer (eds.), Inquisitorial Inquiries..., p. 3

6 Ibidem, p. XI.

7 Véase María del Pilar Rábade Obradó, "Los 'tiempos' de la Inquisición durante el reinado de los Reyes Católicos”, en Manuel González Jiménez (ed.), La Península en la era de los descubrimientos, 1391-1492. Actas de las III Jornadas Hispano-Portuguesas de Historia Medieval, 2 vols., Sevilla: Junta de Andalucía/ Consejería de Cultura y Universidad de Sevilla, 1997, vol. I, pp. 321-330.

8 Monique Zerner, "Herejía”, en Jacques Le Goff y Jean Claude Schmitt (eds.), Diccionario razonado del Occidente Medieval, Madrid: Akal, 2003, 328-339, en concreto p. 328.

9 Kagan y Dyer (eds.), Inquisitorial Inquiries..., p. 5, recuerdan que muchas autobiografías del inicio de la Edad Moderna se adaptan bastante bien a la idea de confesión que era sostenida por la Iglesia Católica; en ellas, se hacía hincapié sobre todo en aquellos aspectos que se consideraban relevantes desde el punto de vista espiritual. Pero la autobiografía espiritual no es una novedad de la Edad Moderna, ya había existido durante el Medievo; tal como explica Jean Claude Schmitt, "Rêver au XIIe siècle", en Tullio Gregory (ed.), I sogni nel Medioevo. Seminario Internazionale, Roma, 2-4 ottobre 1983, Roma: Ed. dell'Ateneo, 1985, pp. 291-316, y en concreto p. 292, desde el siglo XII se produjo el desarrollo de los hábitos de instrospección "en liaison avec la généralisation de la confession auriculaire et le développement de nouvelles pratiques judiciaires destinées à produire l'aveu. 
ración autobiográfica al uso, ya que el reo no pretende ofrecer un relato completo de lo que ha sido su existencia, sino que la información que aporta el acusado se centra, como no podía ser de otra forma, en los aspectos religiosos de aquélla ${ }^{10}$.

La autobiografía espiritual es una de las formas habituales de los llamados ego-documentos ${ }^{11}$. A su vez, los ego-documentos son una de las formas habituales que adopta la llamada autobiografía popular, siempre marcada por "los conflictos y complejidades inherentes en [...] las intenciones de los autores" ${ }^{12}$. En el caso concreto de las peculiares narraciones autobiográficas que se insertan en los procesos inquisitoriales, son el producto de un contexto muy particular, en el que se entremezclan las experiencias vitales de los reos con la intención de los inquisidores de que aquéllos realizaran una confesión ${ }^{13}$.

No se puede olvidar que se trata, al fin y al cabo, de "autobiografías inducidas" ${ }^{14}$, así que en ellas destaca la carencia de espontaneidad que, en principio, se considera que debe de predominar en este tipo de fuentes ${ }^{15}$. Además, el suyo es un relato fragmentado, en el que se resaltan ciertos episodios de la propia vida, mientras que otros resultan absolutamente soslayados: no se puede olvidar que cuando los herejes cuentan su historia ante los inquisidores lo hacen en unas condiciones de absoluta falta de libertad, y presionados por las consecuencias que puede tener su relato. Saben que están luchando por su vida, que han de seleccionar cuida-

Un des effets de cette mutation idéologique et mentale essentielle est l'essor de l'autobiographie". Sobre las características esenciales de la autobiografía espiritual, véase Félix Vernet, "Autobiographies spirituelles", en Marcel Viller, Ferdinand Cavallera y Joseph de Guibert (dirs.), Dictionnaire de spiritualité. Ascétique et mystique. Doctrine et histoire, 45 vols., París, Beauchesne, 1932-1995, vol. I, pp. 1141-1159.

10 En Kagan y Dyer (eds.), Inquisitorial Inquiries..., p. 4, se considera que incluso se podría hablar, directamente, de autobiografía inquisitorial, por sus especiales características, pues se trata de una autobiografía involuntaria, realizada en condiciones de presión, muchas veces desarrollada como consecuencia de las preguntas de los inquisidores. Bibliografía relativa a esta cuestión en este mismo trabajo, p. 6, nota no 5 .

11 Véase Rudolf S. Dekker, "Jacques Presser's Heritage: Egodocuments in the Study of History", Memoria y civilización, 5 (2002), 13-37; James S. Amelang, "Los dilemas de la autobiografía popular", Trocadero, 16 (2004), 9-17 y en concreto pp. 9-10, ofrece una adecuada definición de esta categoría documental: "toda forma literaria en primera persona que expone o revela experiencias personales".

12 Amelang, "Los dilemas..." , p. 10.

13 Kagan y Dyer (eds.), Inquisitorial Inquiries..., p. 5.

14 Así las ha definido, acertadamente, Antonio Castillo Gómez, Entre la pluma y la pared: una historia social de la escritura en los siglos de oro, Madrid: Akal, 2006, p. 11; considera que las "discursos de vida" y otros relatos de índole autobiográfica que se incluyen en los procesos inquisitoriales están "condicionados por las expectativas del destinatario que los ha solicitado", que es, lógicamente, el inquisidor, con todo lo que esto implica (p. 126).

15 Amelang, "Los dilemas... ", p. 10. Muy significativo es el título de un breve trabajo de Richard L. Kagan, "Involuntary or Inquisitorial Autobiography", Cultura Escrita y Sociedad, 1 (2005), pp. 92-94. 
dosamente sus palabras, como también han de seleccionar cuidadosamente los episodios sobre los que se va a articular su discurso y los detalles que lo van a adornar. Esos episodios, esos detalles, se centran en las cuestiones más diversas y variopintas que nos podamos imaginar: ascendencia familiar, circunstancias en las que se desarrolló la infancia, vida profesional, relaciones personales...

La presión que los inquisidores ejercían sobre los reos dio lugar a relatos autobiográficos de la más diversa índole ${ }^{16}$. En algunos casos, los reos internalizaban, de alguna forma, la importancia de la confesión, así que hilvanaban relatos en los que predominaba el afán por conseguir la misericordia de sus jueces, muchas veces de forma un tanto candorosa. En otros casos, el relato de la propia vida estaba presidido por un evidente afán justificatorio, de defensa frente a las acusaciones de los inquisidores. En ocasiones predominaba el esfuerzo por cargar las culpas sobre las espaldas de otros, que habrían inducido al reo a desviarse del recto camino.

Evidentemente, estos relatos autobiográficos son de extensión muy variable: mientras que en algunos casos pueden ocupar varios folios dentro del proceso inquisitorial, también los hay de apenas un párrafo ${ }^{17}$. Todo esto, sin olvidar que los relatos autobiográficos no siempre eran absolutamente veraces y que eran el resultado de las transcripciones que realizaban los notarios inquisitoriales, con lo que esto puede implicar ${ }^{18}$.

Pero las trazas autobiográficas no sólo se deslizan en las propias confesiones de los reos, también lo hacen en otras partes del proceso inquisitorial. Son de sumo interés los datos que sobre el reo nos van ofreciendo los otros protagonistas del proceso, esencialmente los testigos, tanto de cargo como de abono. En efecto, los testigos arrojan luz sobre algunos episodios de la vida del acusado, aunque en este caso el relato está todavía más fragmentado que el de los propios reos. Evidentemente, una vez más son retazos biográficos marcados por el signo de lo religioso, pero junto a ello aparecen referencias de índole muy diversa, con frecuencia estrechamente vinculadas con la vida cotidiana de los acusados.

También se obtienen ricos datos autobiográficos de los llamados pliegos de tachas. Los pliegos de tachas eran el instrumento utilizado habitualmente por los reos para tratar de desembarazarse de las acusaciones que contra ellos lanzaban los testigos anónimos. En ellos trataban de demostrar que dichas acusaciones eran falsas, recurriendo al relato de episodios del pasado en los que parecía quedar patente la enemistad que les profesaban aquellas personas que consideraban que habían testificado contra ellos. Por ese motivo, los pliegos de tachas son muy interesantes para la reconstrucción de las biografías de los reos, ya que se refieren

16 Kagan y Dyer (eds.), Inquisitorial Inquiries..., p. 6, han esbozado una clasificación que se va a seguir en este epígrafe.

17 Tal como recuerda Amelang, "Tracing Lives...", p. 33.

18 Kagan y Dyer (eds.), Inquisitorial Inquiries..., p. 6. 
a episodios muy diversos y variados, a veces muy alejados en el tiempo, marcados habitualmente por el signo de la cotidianeidad, muchas veces esquiva en la documentación medieval.

Algunos ejemplos Del uso De PROCesos inQuisitoriales COMO FUentes BIOGRÁFICAS

Veamos algunos ejemplos de cómo se pueden utilizar los procesos fechados en los primeros tiempos de la Inquisición para biografiar a los reos, aunque carezcan del "discurso de su vida" que se hizo habitual a partir de los años centrales del siglo XVI. Eso sí, antes de seguir adelante, se hará una puntualización absolutamente imprescindible: en las siguientes páginas se ofrecen datos sobre las biografías de los personajes estudiados sin realizar apenas referencias a las cuestiones propiamente religiosas, que tanto espacio ocupan, lógicamente, en las causas de fe. Además, los datos biográficos se ofrecen abreviados, la riqueza biográfica de los procesos es mayor que la que aquí se reseña, tan sólo a modo de ejemplo.

\section{EL CASO DE ANDRÉS GONZÁLEZ DE ALÍA}

Son relativamente habituales los procesos en los que los reos se explican largamente, recurriendo a confesiones que pueden ser tanto orales como escritas. Frecuentemente, esas confesiones no se realizan en una única ocasión, sino en momentos diferentes, a veces incluso muy separados en el tiempo, ofreciendo en ocasiones versiones no totalmente coincidentes de lo que había sido la propia vida, siempre, evidentemente, con una especial inclinación hacia lo que había sido la vivencia religiosa. Un buen ejemplo es el de Andrés González de Alía ${ }^{19}$, procesado en 1486 . Antes de que se iniciara el proceso, y estando ya preso en las cárceles inquisitoriales, el reo presentó dos confesiones ante los inquisidores (la primera el seis de agosto de 1485 , la segunda el doce de noviembre de ese mismo año), en las que hacía un breve repaso de su vida, insistiendo, como no podía ser menos, en sus aspectos religiosos.

La información biográfica que aportan estas dos confesiones es de una gran riqueza. Veamos, muy rápidamente, los datos más importantes que en ellas se ofrecen, empezando por la primera, bastante ordenada de acuerdo con un evidente hilo cronológico, concebida, sin ningún lugar a dudas, para captar la benevolencia de los inquisidores, para convencerles de que era un hombre consumido por las dudas religiosas, fácilmente influenciable por los que formaban su entorno.

19 María del Pilar Rábade Obradó, "Las dudas del hereje: el proceso inquisitorial contra Andrés González de Alía (1486)", Mundos medievales: espacios, sociedades y poder. Homenaje al profesor José Ángel García de Cortázar y Ruiz de Aguirre, 2 vols., Santander: Universidad de Cantabria, 2012, vol. 2, pp. 1801-1812. 
Nuestro hombre se presenta a sí mismo como hijo de una familia cristiana devota, a pesar de su ascendencia judía, en la que los padres les impusieron a él y a sus hermanos en la religión cristiana. Recuerda que se mantuvo firme en la fe cristiana hasta que, oficiando como sacerdote en la localidad de Herrera, fue impuesto en el criptojudaísmo por Alonso González Donoso, a través del cual conoció a García, hijo de Diego González de Puertopeña, en cuya casa se reunían los judaizantes.

Sus escarceos con el criptojudaísmo terminaron con su marcha de Herrera, pero todo volvió a empezar unos años después, cuando era capellán de Alcaudete; allí conectó con una familia de conversos que eran famosos en la localidad por sus prácticas judaizantes, los Marqués. Si se han de creer las palabras de Andrés, se aproximó a ellos para tratar de devolverles al redil de la Iglesia, también para protegerles de las iras de sus convecinos, que un domingo se conjuraron para atacarles, aunque el sacerdote logró evitar que lo hicieran.

En un principio, al cabeza de familia, Gonzalo, le asustó la intervención del clérigo, pero una vez que supo que era de origen judío se tranquilizó, y lo que hizo fue trabajar para atraerle al criptojudaísmo, cosa que logró sin demasiado esfuerzo. Por si esto fuera poco, Andrés se enamoró de una hermana de Gonzalo, Isabel. Cierto es que no era la primera vez que el sacerdote quebrantaba el celibato: ya lo había hecho antes, en una etapa en la que no realizaba prácticas judaizantes, y de esa relación había nacido una criatura, que no tardó mucho en morir, siendo seguida a la tumba por su desafortunada madre; pero, al fin y al cabo, Andrés no era, ni mucho menos, el único eclesiástico que quebrantaba el celibato, pues era esto algo muy frecuente.

El problema principal, en relación con sus amoríos con Isabel, era que ella era judaizante, y que su relación hizo que él se hundiera todavía más en ese tipo de prácticas. Las cosas llegaron hasta tal punto, que se casaron según el rito judío, comportándose, cuando podían, como marido y mujer.

Sus relaciones con los Marqués le pusieron en contacto con otros criptojudíos, cuyos nombres se enumeran en la confesión, para delicia de los inquisidores, que sin ninguna duda se valieron de tan rica información para basar parte de su actividad procesal. Inmerso en la espiral de criptojudaísmo, Andrés aprovechó algunos viajes a Talavera para tratar de saciar ciertas curiosidades relacionadas con sus nuevos amigos. Así, entró alguna vez en la sinagoga, para ver cómo eran las celebraciones mosaicas, e igualmente acudió a un judío de esa localidad que se ganaba la vida enseńando hebreo a los hijos de sus correligionarios, para que también le enseńara a él; evidentemente, el judío no quiso comprometerse a hacer algo que le podía costar muy caro, pero transigió en regalar al sacerdote un libro con oraciones judías traducidas al romance, similar al que empleaban otros judeoconversos cuando judaizaban.

Mientras todo esto sucedía, Andrés seguía siendo sacerdote y actuando públicamente como tal; por tanto, llevaba una doble vida, que no dejaba de pasarle 
factura. Por un lado, su cercanía con los Marqués levantaba sospechas en el pueblo, y más de uno de sus feligreses empezaba a considerarle un mal cristiano; por otro lado, las dudas religiosas que le habían atenazado desde que se inició por primera vez en las prácticas judaizantes volvían a hacerse muy presentes. Aunque durante esa etapa de su vida creía en el Dios de los judíos, no dejaba de temer al Dios de los cristianos, pese a que esto pueda resultar paradójico. Así, cada vez que comulgaba temía que la cólera del Dios cristiano se haría patente, obrando algún milagro con consecuencias espeluznantes para él.

La tortura en la que se había convertido su vida cesó cuando los Marqués decidieron trasladarse a Toledo. Él debía de permanecer en Alcaudete, de modo que aprovechó para cortar sus relaciones con la familia de criptojudíos. A partir de ese momento, dejó de lado las prácticas judaizantes, se deshizo de los libros de oraciones judías que tenía en su poder, y se confesó con un sacerdote amigo suyo, Alonso López Hidalgo, que le dio la absolución, aunque Andrés no relató sus errores de forma pormenorizada.

La segunda confesión es muy diferente a la primera. Desordenada y asistemática, parece reflejar el derrumbamiento del reo tras los meses pasados en las cárceles inquisitoriales. Pero eso no es todo: en su segunda confesión, Andrés revela datos sumamente incriminatorios, de tal forma que la citada confesión le conducía, casi irremediablemente, a la muerte en la hoguera.

Asombrosamente, el sacerdote reconocía en su segunda confesión que había sido criptojudío desde que, en su infancia, pasó una temporada con su abuelo, Fernando García Cabeza de Oro, entre Guadalupe (a unos 14 kilómetros de Alía, su localidad natal) y la Puebla de Alcocer, residencia habitual de aquél. Según afirma Andrés en su segunda confesión, el abuelo aprovechó también esos días para circuncidarle, lo que provocó la cólera de su padre cuando se enteró; el enfado fue de tal calibre, que los dos hombres nunca volvieron a dirigirse la palabra, y el progenitor de Andrés ni tan siquiera acudió al entierro del abuelo cuando éste falleció.

Desde ese momento, ya no cesó en sus prácticas judaizantes, y fue ese el motivo, y no otro, por el que se acercó a los Marqués poco después de llegar a Alcaudete. Si se hizo sacerdote, si dio muestras de ser cristiano, fue siempre por disimulo, igual que fue el miedo, y no el arrepentimiento, lo que le llevó a confesarse tras la marcha de los Marqués de Toledo.

Asimismo, Andrés reconocía haber protagonizado habitualmente algunas prácticas en escarnio del cristianismo, como, por ejemplo, no dar la absolución a los que se confesaban con él, u orinar, cuando daba largos paseos por la calles de Talavera, en un rincón apartado y discreto, justamente debajo del Crucifijo que estaba colocado allí. También fue testigo del proselitismo realizado por Gonzalo y los suyos, aunque nunca hizo nada por evitarlo.

Igualmente, relataba haber tenido conocimiento de comportamientos inadecuados por parte de otros clérigos, sin haberlos denunciado. Uno de ellos, vincu- 
lado con la manera en que un amigo suyo, Juan Sánchez, se había ordenado sacerdote; como no estaba suficientemente preparado, convenció a un tercer amigo, Alonso López Golente, que debía de ser mucho más aplicado, para que acudiera a examinarse en su lugar. La triquińuela dio resultado, y Juan Sánchez consiguió la ansiada ordenación sacerdotal. Otro, la frase que Juan, santero de San Andrés de Talavera, le había dicho que había oído decir a Ruy López, párroco de San Salvador, que "avía renegado de un Dios, y del otro, y del otro".

La lectura de las dos confesiones de Andrés González de Alía plantea, como no podía ser de otra forma, algunos interrogantes, no precisamente baladíes. La presentación de la segunda hace evidente que la primera no respondía totalmente a la realidad: en ella se describen episodios que efectivamente sucedieron, aunque es evidente que son presentados obviando los detalles más incriminatorios, incluyendo observaciones sobre los propios sentimientos que no se correspondían con la verdad, pero que podían resultar muy útiles cuando, como era el caso, se estaba luchando por la propia vida.

Sin embargo, la segunda confesión del sacerdote parece ser el resultado del derrumbe, de la confusión intelectual provocada por las privaciones de varios meses de cárcel. Finalmente, también es posible que las reflexiones de esos difíciles meses de encarcelamiento hubieran provocado en Andrés una auténtica conversión religiosa: la confesión habría respondido, entonces, a la necesidad de limpiar su conciencia, para así poder reiniciar una nueva vida. Sea como fuere, Andrés acabó pagando tanta sinceridad con su propia vida.

\section{EL CASO DE JUAN DE PINEDA}

En algunos casos, el relato autobiográfico que se ofrece a los inquisidores está claramente trucado. Ese fue el caso de Juan de Pineda, procesado también en $1486^{20}$, que, aunque no presentó ninguna confesión ante los inquisidores, sí que relató ante ellos, en diversas circunstancias y momentos del proceso, algunos de los acontecimientos más destacados de su existencia. Pineda fue revelando los datos de su pasado que más le podían favorecer; pero, al mismo tiempo, se esmeró por ocultar otra parte de su pasado, aquélla que estimaba que le podía perjudicar.

Pineda se presentó a sí mismo como descendiente de cristianos viejos, negando, por tanto, que la sangre judía circulara por sus venas. Estaba avecindado en Toledo, aunque no indica la colación, y allí vivía pacíficamente con su mujer, cuyo nombre no se expresa en ningún momento del proceso, hija del hidalgo Esteban de Sosa, que durante algún tiempo había sido jurado en la citada ciudad. La pareja tenía varios hijos, aunque sobre ellos no se ofrece ningún dato concreto,

20 María del Pilar Rábade Obradó, "Un cordobés ante la Inquisición de Toledo: el proceso contra Juan de Pineda (1486)", Córdoba y la época de Isabel la Católica, Córdoba: Publicaciones de la Real Academia de Córdoba, 2006, 171-189. 
Pineda se jactaba de la elevada posición social y económica que había alcanzado, de los vínculos que había establecido con personas de elevada alcurnia. Así, recordaba su cercanía con Enrique IV y dos de los dignatarios más destacados de la corte del difunto monarca, el arzobispo de Toledo Alfonso Carrillo y el Marqués de Villena y Maestre de Santiago Juan Pacheco. La relación con este último fue clave para Juan de Pineda, como lo fue también su vinculación con el papa Sixto IV.

Precisamente fue Pacheco el que envió a Roma a Pineda, juntamente con el prior Juan de Valenzuela, para gestionar algunos asuntos de la Orden de Santiago. Se puede deducir del proceso que debió de viajar hacia finales de 1473, quizá ya iniciado 1474. En Roma vivió una larga temporada, durante la cual consiguió el favor del pontífice, que, entre otras cosas, le designó conde del sacro palacio.

También de acuerdo con la información que se ofrece en el proceso, regresó de Roma antes de 1482, año en el que falleció Carrillo, pues estuvo viviendo con él durante algún tiempo, mientras esperaba que se resolvieran los problemas relacionados con la toma de posesión de la encomienda de Alpajes; porque, efectivamente, Pineda regresó de Roma con una encomienda de Santiago en el equipaje.

A nuestro hombre no le resultó sencillo hacerse con su encomienda, pues hubo de enfrentarse a un pleito con otros caballeros de la Orden, que también la codiciaban. Al final, logró triunfar, gracias, fundamentalmente, al apoyo que le dispensó Sixto IV. Da toda la impresión de que cuando se inició el proceso no llevaba demasiado tiempo disfrutando de su posesión.

Finalmente, y como es habitual en estos casos, nuestro hombre insistió en toda una serie de prácticas cristianas que avalaban su condición de devoto seguidor de Cristo. En honor a la verdad, las muestras de devoción cristiana no eran muchas, se limitaban a la recitación de las oraciones habituales, la realización de los preceptivos ayunos, la presencia en Misa en domingos y festivos, la frecuentación de las sacramentos de la penitencia y la eucaristía, el cumplimiento de las costumbres gastronómicas que se esperaban en un cristiano y la compra de indulgencias.

La narración de Pineda sobre los aspectos más destacados de su existencia tuvo que enfrentarse a los testimonios de varios de los testigos que declararon en su causa de fe; entre ellos, por cierto, algunos de relieve, sobre todo entre los de abono, lo que demuestra la posición social y económica que había alcanzado el reo. A través de dichos testimonios, el relato de nuestro hombre se ve complementado e incluso, en algún caso, rectificado. Además, hay que aclarar que no sólo los testigos de cargo contra nuestro hombre revelaron aspectos de su pasado que éste pretendía sepultar en el olvido, sino que también lo hicieron algunos de los testigos de abono.

Y las rectificaciones no son precisamente menores. Para empezar, varios testigos afirmaron que Juan de Pineda se llamaba, en realidad, Juan de Baena; esos mismos testigos insistieron en su condición de judeoconverso por parte mater- 
na (parece ser que su padre era cristiano viejo), al tiempo que recordaban los problemas de su familia con la Inquisición. Concretamente, el Santo Oficio había juzgado a un pariente suyo, quizá hermano, que respondía al nombre de Gonzalo de Baena, sastre, que había sido reconciliado, igual que una hermana suya, de nombre desconocido, que podría, por tanto, ser también hermana de Juan de Pineda.

Asimismo, desvelan algunos aspectos del pasado del reo que éste no había relatado a los inquisidores. Era natural de Córdoba, localidad en la que había residido hasta el tumulto anticonverso de 1473, concretamente en la calle de la Feria, en la colación de San Pedro, donde había una importante concentración de artesanos y comerciantes, muchos de ellos de origen judío. Por aquel entonces, era un hombre humilde, que había trabajado como sastre hasta el alboroto anticonverso, momento a partir del cual se convirtió en dorador.

Igualmente, algunos testigos afirmaron que durante su estancia en Roma se había movido frecuentemente entre los judeoconversos establecidos en esa urbe; entre ellos, y muy significativamente desde el punto de vista del testigo que lo declaró, se había relacionado con el canónigo de Sevilla Rodrigo de Jaén, que había llegado a Roma precisamente huyendo de la Inquisición.

¿Son totalmente de fiar las declaraciones de los testigos? Esta pregunta es de difícil respuesta en algunos casos. Parece evidente que declaran la verdad cuando varios de ellos coinciden en ofrecer algunos detalles sobre la vida pasada de Pineda, como, por ejemplo, el relativo a su nombre inicial, Juan de Baena; sin embargo, en otros casos es más complicado tratar de determinar si los testimonios son absolutamente veraces. Véase, por ejemplo, el caso de Juan del Río, para más inri testigo de abono de Pineda, que prestó un testimonio que en nada le favoreció, en el que incluso le acusó de ser bígamo, culminando, así, unas declaraciones en las que los chismorreos y la maledicencia parecen tener mucha cabida.

Pineda trató de mantener su versión de lo que había sido su vida. Insistió en que era cristiano viejo, enredándose en una farragosa argumentación a través de la cual pretendió demostrar que no era el hijo de la judeoconversa con la que había casado su padre, si no de otra mujer, por supuesto cristiana vieja. Negó que el suyo fuera un origen humilde: nunca había trabajado ni como sastre, ni como dorador, aunque sí que dijo que tiempo atrás había acudido a Córdoba con el encargo de la Orden de Santiago de hacer dorar veinte jaeces de caballo; como hablaba mucho con los artesanos que tenían el encargo, para que no hicieran trampas con el oro, bien pudo alguno confundirle con uno de dichos artesanos.

Si entretejemos el relato que Pineda hace de su vida con el que nos ofrecen los testigos, tenemos la posibilidad de aproximarnos de forma mucho más fiable a su biografía, que acaba resultando realmente un tanto novelesca. Eso sí, no es posible contestar a la pregunta clave: ¿cómo pudo un humilde judeoconverso cordobés llegar a ser comendador de la Orden de Santiago? Quizá, la clave la 
tenga ese cambio de oficio, que hizo que nuestro hombre dejara de ser sastre para convertirse en dorador, porque jacaso fue uno de los artesanos encargados de dorar esos veinte jaeces de caballo a los que se alude en el proceso? No se puede descartar, y tal vez esa circunstancia fue, para el que entonces todavía era Juan de Baena, la oportunidad de iniciar una nueva vida.

En cualquier caso, la biografía de Juan de Pineda demuestra cómo los judeoconversos, combinando un cambio de apellido con un cambio de residencia y un poco de suerte, podían iniciar una nueva vida, sin el estigma de la ascendencia judía. Aunque la aventura de nuestro hombre terminó mal, en las hogueras inquisitoriales, cabe preguntarse cuántos consiguieron borrar la huella de su origen y triunfaron allí donde Pineda fracasó, trocando la ascendencia hebrea por otra cristiana vieja, con todo lo que esto implicaba.

\section{EL CASO DE FERNANDO DE LA FUENTE}

Veamos un último caso, el de Fernando de la Fuente, un veterano de las guerras de Granada que fue juzgado por la Inquisición entre 1505 y $1506^{21}$. El encausado era hombre más de acción que de palabras, así que las que salieron de su boca durante el proceso no aclaran demasiados aspectos de su trayectoria biográfica. Los testigos arrojan más luz sobre su vida. Pero, en este caso concreto, los detalles biográficos más sabrosos se extraen del pliego de tachas, que, además, es singularmente extenso.

La inusual extensión del pliego de tachas está relacionada muy estrechamente con la facilidad que tenía nuestro hombre para granjearse enemigos, así que, cuando se inició su proceso inquisitorial, tenía motivos para pensar que al menos una parte de esos enemigos habían estado dispuestos a deponer falsamente contra él ante los inquisidores. Presto a desenmascararlos, el antiguo soldado presentó su voluminoso pliego de tachas, que tiene como hilos conductores el mal carácter de Fernando de la Fuente y su inclinación a ejercer la violencia.

Gracias a la combinación de las palabras autobiográficas del veterano de Granada, los detalles que ofrecen los testigos y, sobre todo, el pliego de tachas, podemos reconstruir algunos aspectos de su biografía.

Cuando se inició su proceso, debía tener unos cuarenta años y estaba muy quebrantado de salud. No sólo se le conocía como Fernando de la Fuente, pues también se había hecho llamar Fernando Gómez y Fernando de Soto. Era hijo de Pedro de la Fuente (ya difunto cuando se inició el proceso de su vástago), que había sido fiscal del tribunal del arzobispado de Toledo y jurado en esa ciudad.

21 María del Pilar Rábade Obradó, "El proceso inquisitorial contra Fernando de la Fuente, veterano de la guerra de Granada (1505-1506)", en Ma Isabel del Val Valdivieso y Pascual Martínez Sopena (dirs.), Castila y el mundo feudal. Homenaje al Profesor Julio Valdeón, 3 vols., Valladolid: Junta de Castilla y León/ Consejería de Culura y Turismo y Universidad de Valladolid, 2009, vol. 2, pp. 319-331. 
Nuestro hombre también estaba avecindado allí, y había ejercido efímeramente como jurado.

Fernando era bien conocido en Toledo, esencialmente por su carácter violento y por su facilidad para llegar a las manos con aquéllos con los que reñía. Entre los que tuvieron que soportar su ira, sus vecinos, los Sorje, que también eran judeoconversos. El ama de casa, pese al carácter colérico de su vecino, parecía empeńada en enojarle, pues, según Fernando, se dedicaba a dejar junto a la puerta de su casa restos de basura y agua sucia, hasta que un día nuestro hombre se enfadó; escenificó su enojo persiguiendo a caballo a la vecina hasta el interior de su casa, puñal en mano, con las peores intenciones.

El dueño de la casa trató de calmar a su irascible vecino, pero no lo consiguió fácilmente. Apeló a que todos ellos compartían la condición de judeoconversos, pero eso no sirvió de mucho, Fernando le contestó con una retahíla de insultos, que terminó recordando que los padres de su vecino habían sido quemados por la Inquisición, así que, en su opinión, ella se merecía plenamente la calificación de "puta judía” que le dedicó.

Otros vecinos de Fernando también sufrieron sus ataques de cólera, como Juan Gutiérrez y su mujer. El veterano soldado estaba un día haciendo sacar estiércol de su casa cuando parte de ese estiércol fue a caer delante de la puerta de la pareja; la mujer salió a barrer, echando el estiércol sobre la puerta de Fernando, que respondió con la violencia habitual, insultando gravemente a sus vecinos.

Concretamente, nuestro hombre era vecino de la colación de Santa Leocadia, donde estaba en posesión de una casa lo suficientemente amplia como para tener alquiladas varias de sus habitaciones a diversas personas, lo que le permitía paliar una situación económica no precisamente buena, pues, aparte de la casa, prácticamente lo único que poseía era su caballo y su equipo de guerra. De esto se deduce que debía de haber dilapidado la herencia paterna, por cuya posesión se había enemistado con su hermana, Catalina, hasta el punto de considerar que podía haber levantado contra él falso testimonio.

Fernando estaba soltero, aunque había estado desposado en el pasado, pero el matrimonio no llegó a consumarse, ya que su prometida falleció prematuramente. De las palabras del veterano de guerra se deduce que ella era un buen partido, ya que gozaba de una cuantiosa dote, 50.000 maravedíes; aunque no se llega a desvelar su identidad, quizá era hija de su madrastra, Marina de Soto, de condición hidalga.

A pesar de su soltería, los líos de faldas fueron una constante en la existencia de Fernando, tal como parecen indicar las páginas de su pliego de tachas. El más sonado fue el que le vinculó con una tal Leonor Núñez; su marido se enteró de lo que pasaba a través de la tía de la criada de su esposa y decidió hacer justicia a su modo: mató a su mujer, pero también a la criada, que trató de defenderla. El suceso implicó no sólo la hostilidad del marido ultrajado, sino también la de 
los parientes de las dos difuntas. Otro caso: los amoríos del veterano soldado con Teresa Páez, con la que tuvo una hija, a pesar de que eso fue cuando estaba desposado; cuando su esposa murió, Teresa empezó a perseguir a Fernando para que se casara con él, a lo que él se negó, de modo que Teresa y todos sus parientes se enemistaron con él.

Junto a los líos de faldas, el reo tuvo también frecuentes problemas económicos, que se reflejan claramente en el pliego de tachas. Precisamente, esas dificultades le animaban a poner toda la carne en el asador cuando se le debía algún dinero, circunstancia que, si hay que creer sus palabras, debía ser bastante habitual, y suscitaba fuertes enemistades, así como ansias de venganza por parte de los presionados. Así, el dinero que le debían Juan de Villalba y sus hijas, que tenían unas cámaras alquiladas en su casa, fue el motivo de la enemistad que les enfrentó con Fernando.

También las deudas motivaron las desavenencias entre el veterano soldado y el valenciano Gazara Sánchez. Este, su mujer y su hija vivieron algún tiempo en unas habitaciones en casa del reo, pero se retrasaban habitualmente en el pago del alquiler, lo que envenenó la convivencia; Fernando, tal como era habitual en él, se dejaba llevar por su mal carácter, así que dedicaba frecuentes insultos a sus inquilinos, muchas veces relacionados con su condición de cristianos nuevos, algo que chocaba brutalmente con sus ínfulas de hidalguía.

El hecho más destacado de la existencia de Fernando fue su participación en las guerras de Granada, en la década de los ochenta, cuando fue hombre de armas en las capitanías de Pedro del Castillo y Sancho de Rojas, consecutivamente. Sabemos que participó en las tomas de Málaga y Baza, como también participó en la represión de la rebelión de los mudéjares que se produjo con posterioridad. Durante sus tiempos como soldado llevó una vida bastante turbulenta, que queda ampliamente reflejada en su pliego de tachas.

Fueron frecuentes las disputas con los criados que le servían, a los que solía maltratar, como pasó con Cristóbal, al que despidió sin contemplaciones después de hacerlo azotar. No eran mucho mejores las relaciones que mantenía con sus compañeros de armas: un tal Sayavedra sufrió sus iras cuando ambos estaban prestando sus servicios en el real de Málaga; a Rodrigo Moro le dio varias cuchilladas en la cara después de una discusión; con un tal Fermosilla se batió en duelo después de una partida de naipes en la que ambos se jugaron una importante cantidad de dinero...

Por supuesto, y como no podía ser de otra forma, nuestro hombre también realizó una enumeración de sus cumplimientos como buen cristiano. Sí que es verdad que se trata de una enumeración un tanto sumaria, que no presenta a Fernando de la Fuente precisamente como un hombre devoto. Tan sólo se alude a la recitación de las principales oraciones cristianas, la asistencia a Misa, el cumplimiento con los sacramentos más importantes, las limosnas que entregaba perió- 
dicamente a pobres cristianos y la especial devoción que sentía hacia la Virgen y hacia diversos santos, entre ellos San Cristóbal y San Sebastián, muy populares en ese momento; también, como hombre de su época, tenía la costumbre de tomar indulgencias. En este caso concreto, el pliego de tachas no es de ninguna ayuda, ya que no ofrece ninguna información complementaria sobre estas cuestiones.

Cuando Fernando se vio obligado a enfrentarse al proceso inquisitorial al que fue sometido, no era la primera vez que tenía problemas con el Santo Oficio, aunque en la anterior ocasión salió bien librado, pues no se le llegó a incoar proceso. También había tenido otro tipo de relación con el Santo Oficio, pues, según sus propias palabras, había acudido en alguna ocasión a declarar ante los inquisidores lo que sabía de algunos herejes.

Como es de imaginar, su mal carácter le llevó, inevitablemente, a reñir con oficiales de la Inquisición, tal como se refleja en su pliego de tachas. Nuestro hombre discutió con un tal Barzana, que estaba vinculado con el Consejo de la Inquisición, mientras aquél posaba en su casa, acusándole de ser judío. Después de esa disputa, el afrentado y un portero del Santo Oficio se pelearon con un hermano del acusado, al que habrían dado muerte si éste no le hubiera defendido, dando al portero una cuchillada en la mano por la que estuvo preso durante algún tiempo en las cárceles inquisitoriales y tuvo que pagar una multa de 1.000 maravedíes.

Pese a tales antecedentes, la aventura inquisitorial de Fernando de la Fuente no terminó en la hoguera. Más afortunado que los dos casos anteriores, el antiguo soldado de las guerras de Granada consiguió que la suya fuera una sentencia absolutoria.

Ya que en su caso es el pliego de tachas el principal recurso para reconstruir su biografía, cabe también preguntarse acerca de la veracidad de las noticias que las tachas aportan sobre la biografía del reo. Para contestar a este interrogante hay que recordar cuál era la finalidad del pliego de tachas: librarse de las acusaciones lanzadas por los testigos tachados; por ese motivo, es muy posible que se exageraran los episodios que fundamentaban las tachas, aunque también es cierto que la exageración tenía siempre una limitación, ya que los inquisidores exigían que los reos presentaran testigos que pudieran ratificar las tachas. Incluso, llegado el caso, los inquisidores llamaban a los propios tachados, para tratar de disipar las últimas dudas al respecto. Pero, pese a todo esto, nunca se puede olvidar que el pliego de tachas representa la visión del reo, con todo lo que esto implica.

\section{Conclusiones}

A través de este trabajo se ha tratado de valorar las posibilidades de la utilización de los procesos derivados de la primera actividad inquisitorial para confeccionar las biografías de los reos. Es evidente que las causas de fe presentan toda una serie de elementos que favorecen su uso como fuentes biográficas, pero 
también es verdad que no dejan de tener problemas, que implican que han de ser utilizadas con mucha cautela.

Aunque sobre la base de los procesos inquisitoriales se pueden realizar "biografías apasionantes" ${ }^{22}$, también es cierto que se trata de unas fuentes sobre las que hay que trabajar, volvemos a insistir en ello, con sumo cuidado. Sobre todo, hay que manejar con mucha precaución los relatos autobiográficos de los reos; si el recurso al género autobiográfico como fuente histórica siempre implica grandes cautelas $^{23}$, todavía en mayor medida hay que extremar esas cautelas cuando se utilizan materiales autobiográficos tan peculiares como los que nos ofrecen las fuentes inquisitoriales.

Porque, en efecto, la veracidad de los datos biográficos que se ofrecen en los procesos inquisitoriales es problemática. Las indicaciones biográficas de los reos no siempre estaban determinadas por la sinceridad: incluso, se puede afirmar que, en muchos casos, los reos mentían -o al menos no contaban toda la verdad- para tratar de ganarse la benevolencia de sus jueces. Es necesario recordar, una vez más, que las autobiografías inquisitoriales son inducidas.

Las omisiones, incluso directamente las mentiras, que se incluyen en esos relatos autobiográficos, pueden ser contrastadas y completadas con los datos que ofrecen los testigos, tanto de cargo como de abono; igualmente, pueden ser de suma utilidad los pliegos de tachas, pero tanto unos como otros también tienen sus problemas, tal como se ha tratado de hacer patente en las páginas anteriores.

En cualquier caso, sobre la base de los procesos inquisitoriales se puede intentar biografiar a los reos, si bien los frutos serán siempre biografías incompletas, marcadas por la ausencia de datos esenciales para conocer al detalle sus peripecias biográficas. Pese a todo esto, merece la pena intentarlo, pues ese intento permitirá una aproximación difícil de conseguir a través de la utilización de otro tipo de fuentes.

En efecto, hombres como Andrés González de Alía, Juan de Pineda o Fernando de la Fuente difícilmente podrían haber sido biografiados si no hubieran tenido la desgracia de haber sido víctimas del aparato inquisitorial; fue esa situación la que, a la postre, ha permitido que pasaran a la Historia, aunque sea de manera imperfecta y fragmentaria.

22 José Luis Beltrán Moya; Antonio Espino López y Ricardo García Cárcel, “Antropología...”, p. 27.

23 No está de más traer a colación las palabras de Georges May, La autobiografía, México (D. F.): Fondo de Cultura Económica, 1982, pp. 102-103, que afirma que "la autobiografía no es verídica porque es justamente una autobiografía", entre otras cosas porque "el autobiógrafo no puede escapar del presente en el que escribe a fin de recuperar plenamente el pasado que narra”. 